CATALAN REVIEW

Catalan Review

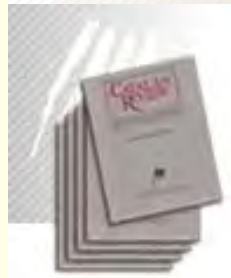

You are accessing the Digital Archive of the Catalan Review Journal.

By accessing and/or using this Digital Archive, you accept and agree to abide by the Terms and Conditions of Use available at http://www.nacs-

catalanstudies.org/catalan_review.html

Catalan Review is the premier international scholarly journal devoted to all aspects of Catalan culture. By Catalan culture is understood all manifestations of intellectual and artistic life produced in the Catalan language or in the geographical areas where Catalan is spoken. Catalan Review has been in publication since 1986 .
NORTH

AMERICAN

CATALAN

SOCIETY
Esteu accedint a l'Arxiu Digital del Catalan Review

A l' accedir i / o utilitzar aquest Arxiu Digital, vostè accepta i es compromet a complir els termes i condicions d'ús disponibles a http://www.nacs-

catalanstudies.org/catalan_review.html

Catalan Review és la primera revista internacional dedicada a tots els aspectes de la cultura catalana. Per la cultura catalana s'entén totes les manifestacions de la vida intel lectual i artística produïda en llengua catalana o en les zones geogràfiques on es parla català. Catalan Review es publica des de 1986.

\title{
Poems of J. V. Foix included in this volume
}

\author{
Catalan Review, Vol. I, number 1, (1986), p. 338-339
}




\section{POEMS OF J. V. FOIX INCLUDED IN THIS VOLUME}

From Sol, $i$ de dol:

Sol, i de dol, i amb vetusta gonella, ...

Oh!, si prudent i amb paraula lleugera ...

Entre negrors veig mil camins oberts ...

I 74

Em plau, d'atzar, d'errar per les muralles ...

Jo tem la nit, però la nit m'emporta ...

És per la Ment que se m'obre Natura ...

Si pogués acordar Raó i Follia,...

179,206

Entre els morats i l'ocre, en carrer clos, ...

En port travat ets l'algosa clapera ...

A tu, reflex d'un altre tu en clausura, ...

¿A quin abís tots dos, a quin repòs, ...

¿Com és la carn, guanyat el goig, d'inerta ...

$¿$ Qui em viu en tu amb joia inseparable, ...

Com vol d'ocells en cel d'abril, afua ...

I 88

El negre i el carmí! Sí, só de borra, ...

I92

Míser i trist apregon la tenebra ...

From Les irreals omegues:

Per a ésser a temps a l'ofertori ...

Passàvem per corriols nocturns ...

$\mathrm{Al}$ peu d'una muralla ciclòpia ...

From $O$ ne deixat les claus...:

Vaig arribar en aquell poble, ...

A l'entrada d'una estació subterrània, ...

Vagava a galop tirat, ...

Fronteres

És quan dormo que hi veig clar 
El meu país és un roc $\quad 292$ Érem tres, érem dos, era jo sol, érem ningú $\quad 296$

From Onze Nadals i un Cap d'Any:

També vindrem, Infant, a l'hora vella ... $\quad 298$

From Desa aquests llibres al calaix de baix:

Es feia fosc ...

Other poems (in verse):

Tot n'és ple

From Gertrudis:

Diuen que estàs gelosa ...

En percebre de lluny el meu rival ...

From $K R T U$ :

KRTU

Notes sobre El Port de la Selva

Presentacions: Salvador Dalí

From L'estrella d'En Perris:

— La cendra és calenta, viatgers! ... 